\title{
GESTO E ABSTRAÇÃO: USOS DO VERBO GOUNOÛMAI EM HOMERO ${ }^{1}$
}

Flávio Ribeiro de Oliveira ${ }^{2}$

- RESUMO: Neste artigo, investigo o significado do ato de suplicação - uma importante instituição social e religiosa na civilização grega - e busco identificar o momento preciso em que, no vocabulário homérico, o verbo gounoûmai (literalmente: "tocar os joelhos de alguém") adquire um valor abstrato ("suplicar, rogar", sem idéia de contato físico com os joelhos).

- PALAVRAS-CHAVE: suplicação, filologia grega, poesia grega, Homero.

\section{I}

A suplicação era uma importante instituição social e religiosa no mundo grego. Nela, uma pessoa ameaçada por dificuldades sérias se dirigia como suplicante a alguém que se encontrasse em situação superior e tivesse condições de lhe dar proteção ou auxílio. Neste artigo, a partir de uma investigação filológica do vocabulário relacionado com a súplica em Homero, pretendo examinar o significado do ato concreto de suplicação - que, em princípio, implicava uma gesticulação bem definida - e analisar a passagem da Odisséia que representa o momento em que a súplica deixa de ser compreendida como gesto concreto do corpo do suplicante e, abstraindo-se, passa a ser concebida como ação verbal.

1 Este artigo é uma versão modificada de trabalho apresentado oralmente em novembro de 2004 no XVIII Simposio Nacional de Estudios Clásicos em Mar del Plata, Argentina. Agradeço ao professor Paulo Butti de Lima, da Università degli Studi di Bari, pela leitura rigorosa deste artigo e por suas valiosas críticas e sugestões.

2 Professor Assistente-Doutor do Departamento de Lingüística do Instituto de Estudos da Linguagem da Unicamp. 


\section{II}

A situação do suplicante no universo heróico descrito na poesia de Homero é uma situação sobretudo concreta. Há, na idéia de suplicação, um elemento concreto fundamental: a postura do corpo, o gesto concreto daquele que suplica. O termo grego que normalmente se usa para designar o suplicante (hikétes) significa concretamente "aquele que chega". Trata-se de nome de agente com sufixo - tes, formado a partir do mesmo radical de verbos como híko, hiknéomai e hikáno (todos com o significado de "chegar"). De hikétes vem o verbo denominativo hiketeúo ("suplicar"). Chantraine (1990, pp.461-2) explica que a idéia original do suplicante seria a do estrangeiro que chega a uma cidade e pede proteção. Essa explicação, contudo, restringe o alcance da idéia da suplicação: na Ilíada e na Odisséia é bem mais amplo o âmbito em que pode ocorrer uma súplica e em que aparecem o termo hikétes e aqueles verbos de cujo radical deriva. As possibilidades de súplica não se reduzem à situação do estrangeiro que chega em determinado país (por exemplo, em situações de batalha, a súplica é pronunciada com freqüência por um soldado que se encontra à mercê do inimigo, independentemente de tal soldado ser ou não estrangeiro). Benveniste (1969, pp.252-4) sustenta que a idéia mesma de suplicação não se encontra apenas no radical isolado hik - ("chegar"), de híko, hiknéomai e hikáno, mas em sua conjunção com o objeto direto goûna ou goûnata (acusativos plurais épicos de gónu, "joelho"): a idéia estaria no gesto de chegar até os joelhos de alguém; o suplicante seria aquele que toca os joelhos da pessoa de quem espera clemência. Há, na poesia épica grega, variantes desse gesto: agarrar os joelhos e beijar as mãos do outro, segurar seu queixo e beijar seus joelhos, segurar-lhe os joelhos e o queixo etc. O suplicante, na cultura grega, adota uma postura corporal que indica inferioridade com relação ao objeto de sua súplica (cf. Gould, 1973, p.94) e o elemento fundamental dessa postura é alguma forma de contato físico entre o suplicante e o joelho daquele que recebe a súplica.

É importante observarmos que a súplica não é uma atitude abstrata ou intelectual: a suplicação é essencialmente um gesto do corpo: no universo épico, é o corpo que suplica. Dois dos verbos gregos que se traduzem por "suplicar", gounoûmai e gounázomai, significam literalmente "tocar os joelhos [de alguém]". ${ }^{3}$

Leaf (1900) vê na ação de agarrar os joelhos e tocar o queixo daquele a quem se dirige a súplica um gesto que simboliza o último recurso do guerrei-

3 Gounoûmai e seu cognato gounázomai aparecem 15 vezes em Homero, sempre em descrições de atos de súplica. 
ro caído e desarmado diante do adversário que está para matá-lo: sua derradeira esperança seria agarrar-lhe os joelhos para atrapalhá-lo e empurrar seu queixo para trás para que ele não possa olhar para baixo e desferir um último golpe certeiro - isso daria tempo ao guerreiro caído de pronunciar seu pedido de clemência. Onians (1988, p.174), com razão, objeta que não há, em nenhuma passagem da literatura grega, sugestões de que o gesto de segurar o queixo de um adversário se destinasse a desviar seu olhar, ou de que o gesto de que agarrar seus joelhos se destinasse a estorvar-lhe os movimentos. Para Onians, os joelhos tinham valor religioso, tinham santidade: o fundamental, no gesto de súplica, seria o contato com essa parte santa do corpo humano (e não a intenção prática de segurar os joelhos do adversário para atrapalhá-lo).

Mas por que, afinal de contas, seria o joelho considerado uma parte sagrada do corpo? Alguns filólogos notaram que o termo gónu parece ser cognato de génos ("raça", "família", "geração", "nascimento") e de gígnomai ("nascer"), do mesmo modo que, em latim, genu ("joelho") poderia ser cognato de genus / generis ("origem", "nascimento") e de gigno ("gerar"). Tentaram-se explicações para tal aproximação entre a idéia de "joelho" e aquela de "nascimento", "geração", "família": Cahen (1926, p.56 ss) sugere que a aproximação se justificaria pela metáfora da família como um corpo humano (o joelho equivaleria, então, a uma ramificação da família). Segundo Back (1922, p.162 ss), a ligação entre o vocabulário relacionado com a geração e o termo que designa o joelho se deveria ao fato de que muitas mães davam à luz ajoelhadas. Meillet (1926, p.45) explica o latim genuinus ("genuíno") como o filho que foi reconhecido pelo pai como autêntico; ora, segundo Meillet, para que tal reconhecimento ocorresse o filho era colocado sobre os joelhos (genua) do pai daí a associação entre os termos que designam os joelhos e a idéia de geração. Segundo Onians (1988, p.175), os povos indo-europeus conceberiam o joelho como sede da paternidade, da vida e do poder gerador. A atribuição de energia viril aos joelhos pode ser encontrada claramente no fragmento 347 (Voigt) de Alceu: segundo o poeta, a canícula torna as mulheres luxuriosas, lascivas, mas torna os homens moles e impotentes, pois o sol "resseca-lhes a cabeça e os joelhos" (kephálan kaì góna... ásdei).

Gould (1973, pp.96-7), concordando com a tese de que os joelhos seriam sede da energia vital e da potência reprodutiva do homem, aventa duas hipóteses (segundo ele, não excludentes) para explicar por que o suplicante buscaria contato físico com tais partes sagradas do corpo do suplicado: uma é a hipótese de que os gregos acreditariam que, com tal contato, a energia vital de quem recebe a súplica fluiria para o suplicante; outra é a de que os joelhos, sendo sede da energia vital, seriam tabu: seriam vistos como uma parte do corpo muito vulnerável, que necessita de proteção. O gesto do suplicante, ainda que inofensivo, seria um contato simbolicamente agressivo com partes do corpo que o suplicado precisaria resguardar. 


\section{III}

Qualquer que seja a explicação filológica ou antropológica que adotemos para dar conta da origem da sacralidade dos joelhos e de sua relação com virilidade e potência geradora, é inegável que os gregos e outros povos indo-europeus concebiam os joelhos como uma das partes nobres, sagradas, do corpo humano - assim como é evidente que o gesto de tocar os joelhos era essencial na atitude de súplica. A súplica era, originalmente, uma manifestação do corpo e o vocabulário da súplica (hikétes, gounoûmai etc.) descreve as formas concretas dessa manifestação. Tal interpretação está de acordo com a reconhecida concretude da linguagem homérica: na linguagem da Ilíada e da Odisséia, não haveria abstração.

Na perspectiva dessa discussão teórica, eu gostaria de analisar brevemente uma passagem do canto VI da Odisséia (versos 119 ss.).

O final do canto $V$ relata o naufrágio de Odisseu. O herói consegue nadar até a terra firme; exausto, procura um abrigo e adormece entre alguns arbustos junto à desembocadura de um rio. O canto VI narra o encontro de Odisseu com Nausícaa, filha de Alcínoo, rei do país a que Odisseu havia acabado de chegar - a terra dos feácios. Odisseu chegara à praia alquebrado, nu e imundo de salsugem. Sua aparência era repugnante (e ele o sabia). Enquanto o herói dormia, a deusa Atena, protetora de Odisseu, inspira em Nausícaa o desejo de se dirigir à foz do rio para lavar roupas. A jovem, acompanhada de suas servas, vai até o local em que o náufrago dormia. As moças começam a brincar com uma bola; seus gritos alegres despertam Odisseu. Ele não sabe a que país chegara; não sabe se seus habitantes são amistosos ou hostis. Está sozinho, sem roupas, sujo: precisará da ajuda daquelas desconhecidas; é imprescindível que suplique a elas para que lhe dêem alguma vestimenta e o introduzam na cidade: sua única esperança é colocar-se na posição de suplicante e obter a benevolência das moças. Ocultando suas partes pudendas com ramos, o herói cuidadosamente se aproxima das jovens. Assim que as servas o vêem, assustam-se com sua aparência horrenda. Todas fogem, aterrorizadas: apenas a princesa Nausícaa permanece onde estava, pois Atena lhe havia infundido coragem no ânimo. Odisseu deteve-se a certa distância da princesa. Nesse momento, põe-se a refletir: sabia que devia suplicar pelo favor da jovem, mas, por outro lado, tinha consciência de sua aparência asquerosa. Portanto, hesitava entre duas linhas de ação: implorar à moça agarrando-lhe os joelhos (goúnon... labòn, verso 142) ou implorar de longe, apenas com palavras, sem tocá-la? Odisseu começa a calcular - como era próprio de sua natureza - e conclui que o mais útil seria dirigir a palavra à princesa de longe, sem tocála: receava que ela ficasse irritada caso ele lhe agarrasse os joelhos (hoi goûna labónti, verso 147). Então, em pé, a certa distância, Odisseu dirige a pa- 
lavra a Nausícaa, iniciando sua súplica deste modo (verso 149): Gounoûmai se, ánassa: theós nú tis ê brotós essi?

Normalmente, esse verso introdutório é traduzido mais ou menos assim: " "Eu te suplico, soberana: és um deus ou um mortal?" Todavia, o verbo empregado por Odisseu (e que os tradutores modernos vertem como "suplico") é gounoûmai, verbo que, até então, carregava o sentido concreto de "tocar os joelhos". Ora, é justamente isto - tocar os joelhos de Nausícaa que Odisseu havia decidido não fazer. Nessa passagem, o verbo gounoûmai perde seu referencial concreto, abstrai-se: designa uma idéia de súplica que não inclui mais o gesto concreto de tocar os joelhos daquele a quem se suplica. Rompeu-se, aqui, a concretude do vocabulário homérico: a palavra, nessa passagem, não é mais uma representação da ação concreta. ${ }^{5}$

O surgimento da abstração na língua grega foi um processo longo, ocorrido em um período histórico que nos deixou poucos documentos escritos. Todavia, esse início do discurso que Odisseu dirige a Nausícaa é um dos lugares privilegiados em que o filólogo pode ver representada a gênese da abstração na língua grega da poesia. Na verdade, nessa perspectiva, o pequeno dilema de Odisseu se agiganta: é como se a decisão a tomar não fosse apenas uma questão de tocar ou não os joelhos da princesa. Odisseu, com sua deliberação e seu discurso, promove uma verdadeira revolução na linguagem. No quadro das discussões teóricas a respeito da origem e da constituição do pensamento racional na Grécia antiga (realizadas com profundidade e fineza por filólogos como Bruno Snell e Richard B. Onians), eu afirmaria, se me concedessem a licença para me exprimir com certa liberdade, que nessa passagem da Odisséia há uma representação poética da invenção do pensamento ocidental.

OLIVEIRA, F. R. de. Gesture and abstraction: employments of verb gounoûmai in Homer. Trans/Form/Ação, (São Paulo), v.29(1), 2006, p.63-68.

- ABSTRACT: In this paper, I investigate the significance of the act of supplication - an important social and religious institution in Greek civilization - and I try to identify the very moment when, in the Homeric vocabulary, the verb gounoûmai (literally: "to touch someone's knees") acquires an abstract value ("to supplicate, to beseech", without physical contact with the knees).

- KEYWORDS: Supplication, Greek Philology, Greek Poetry, Homer.

4 Cf., por exemplo, a tradução italiana de A. Privitera: "Ti supplico, o sovrana: un dio sei forse o un mortale?" (Omero, 1991); e a francesa de M. Dufour e J. Raison: "Je te supplie, ô reine. Es-tu déesse, ou mortelle?" (Homère, s.d.).

5 John Gould qualifica essa espécie de súplica apenas verbal como "figurativa", em oposição à súplica "completa", que inclui os gestos rituais (Gould, 1973, p.77). 


\section{Referências bibliográficas}

BACK, R. "Medizinisch-Sprachliches". Indogermanische Forschungen, XL, 1922.

BENVENISTE, É. Le Vocabulaire des institutions indo-européennes, t. 2. Paris, Minuit, 1969.

CAHEN, M. "Genou, Adoption et Parenté en Germanique". Bulletin de la Société de Lingüistique de Paris, XXVII, 1926. Paris, 1926.

CHANTRAINE, P. Dictionnaire étymologique de la langue grecque. Paris, Klincksieck, 1990.

GOULD, John. "Hiketeia". The Journal of Hellenic Studies, 93, 1973. Paris, 1973.

HOMĖRE. L'Odissée. Trad. M. Dufour e J. Raison. Paris, Garnier, s.d.

LEAF, W. The Iliad, I - II. London, 1900-2.

MEILLET. Comptes rendues de l'Académie des inscriptions et belles lettres. Paris, 1926.

OMERO. Odissea. Trad. A. Privitera. Milano, Mondadori, 1991.

ONIANS, R.B. The origins of european thought. Cambridge, University Press, 1988.

Artigo recebido em 01/06; aprovado para publicação em 05/06. 